\title{
FIGURAS DO IMAGINÁRIO PÓS-HUMANO NA OBRA DE GON- ÇALO M. TAVARES
}

\author{
REPRESENTATION OF THE POSTHUMAN IMAGINARY IN THE \\ LITERATURE OF GONÇALO M. TAVARES
}

\author{
PEDRO CORGA* \\ pedrocorga@gmail.com
}

\begin{abstract}
A literatura de Gonçalo M. Tavares debruça-se sobre questões essenciais da vivência humana num mundo dominado pela constante mudança, pela incerteza, pela ambiguidade e pelo paradoxo. Dada a complexidade do mundo que habitamos, o autor, por diversas vezes, faz referência a um sentido de responsabilidade literária e moral que o escritor de século XXI deve demonstrar, o dever de estar atento ao mundo que o rodeia e de o levar a sério, questionando, refletindo e provocando nos leitores inquietação perante temas tão fundamentais como o destino do ser humano no mundo tecnológico e globalizado do século XXI, a sua relação com a tecnologia, a ciência e as implicações na relação que mantém com o mundo natural. Deste modo, procuramos com o presente artigo encetar uma breve reflexão sobre as características mais marcantes da poética autoral de Gonçalo M. Tavares à luz do conceito do pós-humano, através da leitura das suas mais marcantes produções literárias. As obras pertencentes à tetralogia $O$ reino e títulos como Uma Viagem à Índia, Atlas do Corpo e da Imaginação e Breves Notas sobre Ciência, farão parte desta nossa leitura pós-humana do universo literário de Gonçalo M. Tavares.
\end{abstract}

Palavras-chave: pós-humano; tecnologia; máquina; literatura; natureza; cultura.

The literature of Gonçalo M. Tavares tackles essential issues pertaining to human contemporary life in a world dominated by constant change, by uncertainty, ambiguity, and paradox. The author himself often puts forward the idea of literary and moral responsibility of the writer at the beginning of the 21 st century, the urgency of being aware of the complexity of the world and taking it seriously, questioning and provoking disquiet, restlessness, and discomfort in the reader in the face of such fundamental issues as the fate of the human being in a technological and globalised world, its relationship with technology and science, as well as the human impact on the natural world. This article thus aims at providing a brief analysis of some of the most salient characteristics of Gonçalo M. Tavares's poetics in light of the concept of the posthuman, through a close reading of his most prominent works. The books belonging to the tetralogy $O$ Reino and titles such as Uma Viagem à Índia, Atlas do Corpo e da Imaginação, and Breves Notas sobre Ciência will be included in our posthuman reading of Tavares's literary universe.

Keywords: posthuman; technology; machine; literature; nature; culture.

\footnotetext{
* Investigador Colaborador do Centro de Línguas, Literaturas e Culturas (CLLC) da Universidade de Aveiro. ORCID: 0000-0001-8817-7254
} 
$152 \mid$ PEDRO CORGA

Data de receção: 2020-01-21

Data de aceitação: 2020-09-01

DOI: $\underline{10.21814 / 2 \mathrm{i} .2467}$ 
1.

No universo ficcional de Gonçalo $\mathrm{M}$. Tavares encontramos um ato de escrita que instiga o pensamento e provoca mudança(s) de posição perante a realidade que nos circunda. A sua escrita debruça-se sobre questões essenciais da vivência humana na contemporaneidade, os medos, angústias, motivações e a sua relação com um mundo dominado pela incerteza, pela ambiguidade e o paradoxo. Ao refletir sobre temas desta natureza, o autor chama a si mesmo a "responsabilidade literária e ética" (Tavares, 2010b, p. 37) do escritor no início do século XXI, o dever de estar atento ao mundo e de o levar a sério, questionando e provocando nos leitores inquietação (e até estranhamento) perante temas fundamentais como o destino do ser humano no mundo contemporâneo globalizado e as implicações da relação entre homem, ciência e tecnologia para o equilíbrio no mundo natural. Por meio de um olhar literário atento e vigilante, a sua escrita concretiza uma visão intensamente lúcida, irónica e de forte pendor ensaístico.

Ao longo desta comunicação pretendemos encetar uma reflexão sobre as características mais marcantes da poética de Gonçalo M. Tavares nas relações que mantêm com alguns dos temas centrais das investigações e postulações teóricas desenvolvidas em torno do que que a filósofa pós-humanista Rosi Braidotti chama de "posthuman predicament" (Braidotti, 2013, p. 6). ${ }^{1}$ Procuraremos, igualmente, relacionar a noção de "pessimismo antropológico firme" (Tavares, 2010b) do escritor português com a postura pósantropocêntrica característica da tomada de posição pós-humanista, analisando o modo como o autor reflete acerca do futuro do ser humano na sua relação como os avanços técnicos, tecnológicos e científicos dos nossos tempos. Para tal, iremos debruçar-nos sobre algumas das ideias exploradas amplamente por Tavares em seus textos, com especial destaque para a questão da natureza das motivações humanas e o aproveitamento da tecnologia para a prática do mal. Iremos também abordar a visão que Gonçalo M. Tavares adota perante os acontecimentos contemporâneos, investigando através de uma literatura que desloca o ponto central, focando a sua atenção na margem, observando os fenómenos a partir do canto do olho, com distância atenta e vigilante. Partindo desta abordagem, veremos como esta postura investigativa do autor perante o ato criativo se relaciona com o modo como o posicionamento pós-humano procura desconstruir criticamente e questionar construtivamente as noções de humanismo e antropocentrismo na tentativa de reforçar uma positiva e afirmativa mudança de paradigma, como defende, por exemplo, Rosi Braidotti.

\section{2.}

De acordo com Braidotti, o pós-humanismo opera a crítica e a desconstrução do ideal do "Homem" como suposta medida de todas as coisas (Braidotti, 2018, p. 32). Segundo a autora, a posição pós-antropocêntrica complementa esta prática operando uma crítica ao que ela chama de "species hierarchy and human exceptionalism" (p. 32). No capítulo 2 do seu livro The Posthuman (Braidotti, 2013), Braidotti faz referência ao "post-anthropocentric turn" (p. 57) que visa questionar a noção tradicional de "anthropos", na tentativa de imprimir uma mudança de parâmetros e paradigmas até ao momento encarados como certezas imutáveis e absolutas. O autor alemão Stefan Herbrechter, em Posthumanism -

\footnotetext{
${ }^{1}$ Em The Posthuman, de 2013, Braidotti escreve: "After the postmodern, the post-colonial, the post-industrial, the post-communist and even the much contested post-feminist conditions, we seem to have entered the post-human predicament" (Braidotti, 2013, p. 6).
} 
A Critical Analysis, revela um posicionamento semelhante, defendendo um tipo de póshumanismo crítico que procura investigar "the possible crisis and end of a certain conception of the human, namely the humanist notion of the human" (Herbrechter, 2013, p. 3 ), ao mesmo tempo que procura contribuir para uma transformação acelerada desta última (p. 3).

Por outras palavras, a posição do chamado critical posthumanism envolve um engajamento crítico com a ideologia antropocêntrica do humanismo (Herbrechter, 2013, p. 3). O tipo de pós-humanismo descrito por Herbrechter não cede a euforias nem a nenhuma espécie de misticismo apocalíptico, envolvendo, por um lado, uma abertura à natureza radical da mudança tecnocultural e, por outro, marcando uma certa continuidade com tradições de pensamento que se confrontam criticamente com o humanismo e que, em certa medida, dele fizeram parte (p. 3). Este autor defende, pois, que o potencial de transformação do ser humano através do avanço tecnológico (o chamado processo de póshumanização) é apenas o mais recente sintoma de uma "cultural malaise" (p. 3) que habita o próprio humanismo, tido, neste contexto, como uma ideologia e um específico tipo de discurso. Importa referir que, de acordo com outros teóricos pós-humanistas como Katherine Hayles, "the posthuman view thinks of the body as the original prosthesis we all learn to manipulate, so that extending or re-placing the body with other prostheses becomes a continuation process that began before we were born" (Hayles, 1999, p. 3). Indo mais longe, Braidotti considera que o pós-humanismo do presente é um momento intermédio, um tempo crucial de interceções que conjuga, em simultâneo, o movimento de deixar de ser e o processo de vir a ser. Nas palavras da autora, "to do justice to the complexity of our times, we need to think of the posthuman present as both the record of what we are ceasing to be (the actual) and the seed of what we are in the process of becoming (the virtual). (...) It is not a binary opposition, but the simultaneous occurrence of multidirectional processes" (Braidotti, 2017, p.10). Também para o filósofo francês Bernard Henry-Lévy, a noção de becoming é fundamental para compreender a complexa e dinâmica natureza do humano: "We aren't born human; we become it. Humanity is not a form of being; it is a destiny. It is not a ready state, delivered once and for all, but a process" (Henry-Lévy, 2018). Nesse sentido, poderíamos dizer, como defendem alguns estudiosos e pensadores, que todos nos tornamos pós-humanos a partir do nascimento (ou talvez mesmo antes, considerando os avanços em áreas como as ciências médicas e a biotecnologia).

No entender de Rosi Braidotti, a noção de pós-humano enquanto figuração cartográfica permite, por exemplo, questionar e refletir acerca do fim da categoria Eurocêntrica do "Homem" universal (Braidotti, 2018, p.37), ao mesmo tempo que analisa as potenciais múltiplas formas nas quais o ser humano, nos nossos dias, se está transformando, recompondo ou reestruturando, num claro movimento que se afasta das noções tradicionais de humanismo e antropocentrismo. Para tal, diz-nos Braidotti, a abordagem pós-humana deve ser crítica, criativa e focar-se nas margens de expressão das possibilidades ainda por realizar (p. 7). No entanto, importa referir, como faz Neil Badmington, que o pós-humanismo não pode simplesmente negar ou querer anular por completo o conceito de humanismo: “(...) the 'post-' of posthumanist does not (and, moreover, cannot) mark or make an absolute break from the legacy of humanism. 'Post-' s speak (to) ghosts, and cultural criticism must not forget that it cannot simple forget the past" (Badmington, 2003, pp. 21-22). Para este autor, a escrita e a reflexão em torno da condição pós-humana deve constituir-se como uma prática crítica no seio do humanismo, concebendo-se assim como "the working-through of the humanist discourse" (p. 22). Partindo desta perspetiva, a teoria pós-humanista visa a desconstrução crítica dos valores monolíticos da tradição hu- 
manista, procurando novas formas de entender a natureza do humano no mundo contemporâneo altamente globalizado e tecnológico. Como defende Badmington, esta posição não implica uma rejeição ou negação do valor e da importância do humanismo, do mesmo modo que a tomada de posição pós-moderna (que, de resto, abriu caminho à visão póshumanista) não significa uma rutura ou rejeição total da visão da modernidade. O pós- de pós-moderno e pós-humano não significa rutura, cisão, negação, nem mesmo superação dos conceitos de moderno ou de humano.

Regressando à noção de pós-antropocentrismo, à qual aludimos a respeito de Rosi Braidotti, importa fazer uma breve referência à teórica e filósofa pós-humanista Francesca Ferrando. Esta autora defende a ideia de um "interconnected paradigm" (Ferrando, 2016, p. 4) como uma teia de conexões entre todas as formas de existência que habitam o planeta, não reconhecendo qualquer caráter excecional ao ser humano, considerando-o como uma entre as muitas espécies do nosso planeta, não separado do resto dos seres vivos, mas em íntima conexão com eles. De acordo com esta posição crítica, o bem-estar do ser humano é tão importante como o bem-estar dos animais não-humanos, das máquinas e do ambiente (p.5). Na sua visão filosófica do pós-humanismo, Ferrando coloca ênfase na perspetiva pós-dualista da existência, segundo a qual "no single point of view can be regarded as the complete one" (p.9). Ainda segundo a filósofa italiana, "Epistemologically speaking, Posthumanism is a perspectivism, according to which every perspective is valuable and should be acknowledged and respected" (p.10). Esta noção enconta-se igualmente presente no trabalho desenvolvido por Donna Haraway, nomeadamente o conceito de natureculture enquanto simbiose entre natureza e cultura, outrora elementos considerados apartados, ou mesmo opostos. De acordo com Malone e Ovenden, "Natureculture is a concept that emerges from the scholarly interrogation of dualisms that are deeply embedded within the intellectual traditions of the sciences and humanities (e.g., human/animal; nature/culture)" (Malone, 2017, p. 1). Para Braidotti, na perspetiva teórica e crítica do pós-humanismo qualquer noção de natureza humana é substituída por "“naturecultures' continuum (...)" (Braidotti, 2018, p. 34). Como veremos, a posição de Gonçalo M. Tavares no que diz respeito à relação entre ser humano e natureza é muito próxima da visão pós-humanista, que abandona toda e qualquer ideia de superioridade do ser humano em relação aos outros atores seres vivos habitantes do planeta.

Tendo em conta esta brevíssima passagem por alguns dos posicionamentos teóricos do conceito de pós-humano, poderíamos arriscar dizer que o tipo de abordagem pós-humanista crítica e desconstrutivista proposta por Stefan Herbrechter ou Neil Badmington, e ainda a perspetiva pós-antropocêntrica teorizada por Braidotti e Ferrando, estão em sintonia com a visão antiessencialista, antifundamentalista, pós-dualista, pós-exclusivista (termo amplamente usado por Ferrando), e ainda antropologicamente pessimista, que são a marca essencial da poética autoral de Gonçalo M. Tavares, a começar com os livros pretos da série $O$ Reino, passando pela epopeia Uma Viagem à Índia e Animalescos, até chegar aos últimos dois títulos da recém-criada série Mitologias. Uma posição crítica, desconstrutiva (irónica e desfamiliarizante) e (conceptualmente) criativa, eis a posição que Gonçalo M. Tavares assume perante a realidade contemporânea e pós-humana, da qual veremos, em seguida, alguns exemplos.

\section{3.}

Em primeiro lugar, no que diz respeito à relação entre o homem contemporâneo e o mundo natural, encontramos em Gonçalo M. Tavares marcas definidas de uma visão pós- 
antropocêntrica que rejeita a ideia da primazia e superioridade do ser humano relativamente aos outros seres e formas de vida existentes no planeta, como podemos ver em inúmeras passagens da epopeia tavariana Uma Viagem à Índia. Deste modo, poderemos começar por citar Bloom, o protagonista da referida viagem, em diálogo com o amigo parisiense Jean M. Nesta passagem Bloom refere que "o universo entortou há muito" (Tavares, 2010, p. 130) e que

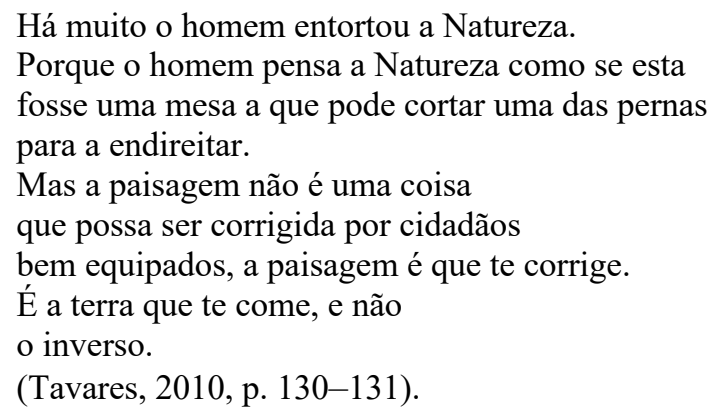

Consideramos que estes versos resumem a posição crítica de Gonçalo M. Tavares em relação à ambição desmedida do homem em querer dominar a Natureza pelo meio da tecnologia e da máquina. Ainda no seguimento dos versos transcritos acima, o narrador refere: "As máquinas executam a parte física/ de uma ordem anterior: dominar o dia/ como se faz à árvore a que se impõe a direcção de crescimento dos ramos. Mas o dia não é matéria controlável" (Tavares, 2010, p. 131). Esta última afirmação sugere que, apesar dos esforços humanos para a subjugar, a Natureza não se deixa domesticar por completo, como indicia a seguinte imagem presente na estância 25 do Canto VI: "A Natureza, de resto,/ é mais ágil no ataque do que na defesa:/ constroem-se cidades em cima de florestas,/ mas debaixo das estradas e dos estabelecimentos comerciais/ há uma vida animal que persiste/ e faz ruído" (p. 256). A propósito desta força (vingativa) da natureza e concluindo, e ao terminar o Canto VI, é referido que, na sua viagem até à Índia, Bloom "sobrevivera à maldade que a natureza/ por vezes tem,/ e sobrevivera à maldade que os homens,/ por hábito, praticam" (p. 283). Note-se a subtil carga irónica das expressões "por vezes" para se referir à maldade dos elementos naturais e "por hábito" quando se refere à maldade humana.

No canto $\mathrm{V}$ da epopeia de Tavares, o narrador, volta a referir-se à mesquinhez e pequenez do homem, cuja soberba se torna ridícula ao pé da força dos elementos e à dimensão do planeta Terra:

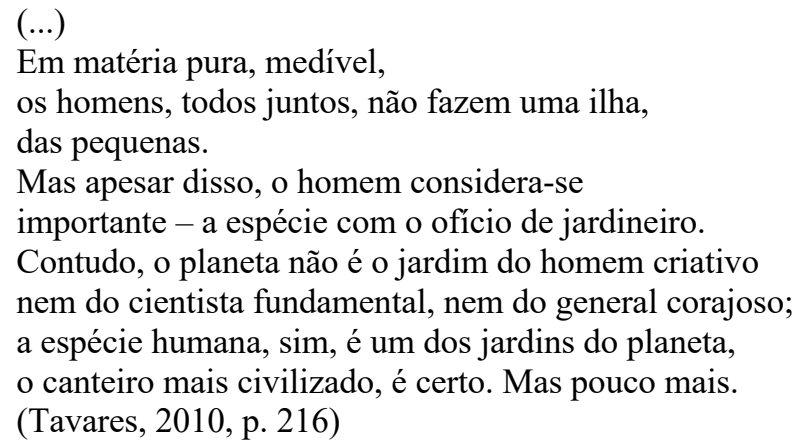

Vemos, pois, na passagem citada, um exemplo da visão de Gonçalo M. Tavares que recusa a ideia da posição central e privilegiada do ser humano em relação às demais espécies, posição que se encontra ainda profundamente enraizada nos hábitos, costumes, e 
modos de pensar e viver da civilização ocidental. Na estância 27 desse mesmo canto V de Uma Viagem à Índia, esta reflexão prossegue, sempre com tom irónico:

Não foi feito para o homem que gosta de doces:

o mel é feito para as abelhas.

E a montanha não existe para que seis homens

organizem uma competição de escalada,

a montanha é uma parte da terra que subiu.

E o mar não tem peixes por o cozinheiro ter inventado

uma forma exótica de os grelhar (...) (Tavares, 2010, pp. 216-217).

$\mathrm{Na}$ estância seguinte, conclui Bloom: "O mundo tem tanta coisa e também tem homens, sim" (p. 217).

Existe, pois, a nosso ver, convergência entre o posicionamento das reflexões literárias de Gonçalo M. Tavares e a visão pós-antropocêntrica defendida pelo posicionamento póshumanista, na qual encontramos a ideia de que o ser humano é apenas um entre muitos outros seres e, como tal, não deve (como o faz) pensar no planeta como seu domínio. Esta mensagem é-nos dada também em Aprender a rezar na era da técnica, último romance da tetralogia $O$ Reino, na passagem que abre o capítulo 2, "A caça", na qual o narrador faz questão de sublinhar a posição de força de Lenz, a sua posição de superioridade sobre todas as coisas, sejam elas humanas (como é o caso da criada sobre a qual o adolescente Lenz avança, na presença do pai), sejam elas não-humanas como é o caso dos "objetos imóveis: as botas, a arma, o colete pesado" (Tavares, 2007, p. 13) que o protagonista veste cerimoniosamente, como um "ritual de domínio" (p. 13) que, segundo o narrador, compreendia movimentos que "eram os que melhor contribuíam para formar o ser humano" (p. 13). Neste preciso capítulo, a superioridade pela força por parte do ser humano Lenz era exercida sobre a natureza, uma vez que, de acordo com esta crua visão antropocêntrica, "os elementos ágeis da natureza reivindicavam uma desobediência que não era tolerável" (p. 13). Esta é, pois, uma posição com um fundo de "determinação política" (p. 13), para que Lenz pudesse assim "tomar uma posição em cima da terra" (p. 13) perante aquilo a que ele chama de "um opositor mesquinho um coelho" (p. 13). Outra passagem que nos mostra esta visão antropológica, que terá, diremos, feito sentido em séculos anteriores, é a referência aos "caminhos que a natureza, com a sua estupidez muito própria, deixara espontaneamente para os homens passarem" (p. 14). Mais adiante, afirma-se que "Lenz não tinha ilusões acerca da terra que pisava: havia entre a natureza e o homem um ponto de ruptura que há muito fora ultrapassado. Existia uma luz nova nas cidades, a luz da técnica, luz que dava saltos materiais que antes nenhum animal conseguira dar" ( $p$. 42).

O Dr. Lenz B era, pois, um cirurgião de uma precisão e frieza incríveis, chegando mesmo a ser comparado com uma máquina: "O pulso de Lenz parecia suportado por um pedaço de metal e não por um braço" (Tavares, 2007, p. 26). Nesta afirmação opera-se uma simbiose entre a técnica do humano e a técnica da máquina, acentuando-se a eficácia e precisão que os aproxima. Aquilo que caracteriza Lenz não é aquilo que é esperado de um ser humano, mas sim aquilo que é esperado de algo que executa com precisão maquinal uma determinada tarefa. Tal ligação surge, igualmente, em A Máquina de Joseph Walser, romance no qual a relação entre o trabalhador Walser e a sua ferramenta de trabalho adquire a forma de uma complexa e estranha proximidade. Atentemos, pois, nesta passagem:

O fundamento da sua existência real aquela máquina era aquilo que permitia à sua família subsistir, era, portanto, aquilo que o salvava, dia após dia, de ser uma outra pessoa (...) mas salvando-o dia após dia essa máquina ameaçava-o também constantemente, sem qualquer pausa. Uma falha na máquina 
que o salvava monotonamente, poderia de um momento para o outro acabar-lhe com a vida ou com o modo de o seu corpo contactar com a vida. (...). Joseph Walser amava a sua máquina, mas sabia que esta o odiava, a ele, humano, de tal como que não o largava de vista; a máquina observava-o constantemente, à procura de uma falha, à espera de uma falha. (Tavares, 2004, p. 22)

Existe na passagem acima transcrita, por um lado, um processo de animização, ou mesmo humanização, da máquina e, por outro, uma espécie de robotização ou maquinalização do ser humano Walser, a quem é pedido concentração precisão, frieza e distanciamento emocional. Era dessa forma, pois, que Walser se deveria aproximar do ser-máquina se quisesse que esta continuasse, dia após dia, a ser a sua salvação.

Em A Máquina de Joseph Walser também se fala da fábrica e do fascínio que a repetição maquinal exerce sobre o ser humano: "Veja esta fábrica: estamos perante o espanto sobrenatural. Tudo é tão estupidamente previsível nestas máquinas que se torna surpreendente; é o grande espanto do século, a grande surpresa: conseguimos fazer acontecer exactamente o que queremos que aconteça. Tornámos redundante o futuro, e aqui reside o perigo" (Tavares, 2007, p. 17), refere o encarregado Klober dirigindo-se a Walser. Nestas palavras menciona-se, então, a relação paradoxal que existe entre a surpresa e o espanto que as máquinas provocam e a previsibilidade que elas perpetuam, uma previsibilidade que tudo presentifica, que tem a potencialidade de anular (ou pior, desvalorizar) o futuro. Rosi Braidotti apelida este mesmo fenómeno de "techno-teratological" (2011, p. 55), segundo o qual, "excitement about the change is coupled with political and social conservatism, nostalgia, and a social climate of anxiety and fear" (p. 55). Comentando esta posição de Braidotti, Herbrechter afirma que a autora encara o presente estado de pós-humanização como resultado de um imaginário cultural profundamente ambivalente e paradoxal, ao mesmo tempo fascinado e aterrorizado pelas monstruosidades "made imaginable and realizable by new technologies" (Herbrecheter, 2013, p.105). Em Atlas do Corpo e da Imaginação, Tavares escreve sobre a relação entre o ser humano e a técnica:

Sempre houve este fascínio por uma parte do mundo, criada pelo Homem, e que avança com certa independência: a técnica. (...) Um corpo que além de ser dispensado (não precisa de supervisionar), pode ser, ele mesmo, substituído e supervisionado pela técnica. (...) Técnica que vai dispensando o movimento, que vai dispensando um conjunto de decisões musculares, essenciais no humano. (Tavares, 2013, p. 99).

Há, portanto, no homem uma parte que ele criou que vai avançando com cada vez maior independência e que vai tornando desnecessários certos movimentos humanos. Esta é, pois, uma possível definição de progresso tecnológico, que vai tornando redundante a ação humana, progressivamente substituída pela máquina. Mais adiante, Tavares conclui, em Atlas do Corpo e da Imaginação: "A tecnologia permite que eu abra a janela sem me levantar, mas, inicialmente, eu, levantando-me, abria a janela à mesma. Eis um paradoxo, ainda mais porque tal é associado ao progresso" (Tavares, 2013, p. 100).

Em Breves Notas sobre Ciência existe um fragmento sobre "Filósofos, cientistas e tecnologia", no qual poderemos descortinar a posição de Gonçalo M. Tavares em relação ao debate homem versus máquina:

A vantagem do filósofo em relação ao investigador rodeado de tecnologias é que o primeiro pode dizer:

- $\quad$ Fui eu que pensei.

Enquanto ao segundo podem acusar, apontando para as maquinarias:

- $\quad$ Foram elas que pensaram.

(Tavares, 2006, p. 136) 
Neste apontamento, Gonçalo M. Tavares usa intencionalmente a palavra "maquinarias" com a intenção de desvalorizar estas em relação ao raciocínio e ao intelecto humano. Tavares coloca, assim, na balança o pensamento filosófico e o pensamento científico do investigador auxiliado pela tecnologia. Obviamente que esta questão não é aprofundada pelo autor (nem será, de momento, nossa intenção fazê-lo), mas consideramos que tal passagem nos permite compreender a posição de Gonçalo M. Tavares que guarda, sempre, uma distância cautelosa em relação às máquinas e ao poder da tecnologia.

Como vemos, quer na sua escrita ficcional, quer nas suas reflexões de caráter mais ensaístico, e mesmo nas suas (sempre reveladoras) entrevistas, a posição de Gonçalo M. Tavares supõe uma atitude de sobreaviso em relação ao envolvimento do ser humano com a tecnologia. Segundo Braidotti, um dos salientes paradoxos da nossa era encontra-se precisamente na tensão entre "the urgency of finding new and alternative modes of political and ethical agency for our technologically mediated world and the inertia of established mental habits on the other" (Braidotti, 2013, p. 58). No caso do escritor português, existe claramente a presença deste paradoxo quando o autor toca o tema da tecnologia, da ciência e as suas implicações para a definição do ser humano na contemporaneidade. No entanto, essa tensão não encontra uma resolução clara nas suas obras de ficção, ainda que pareça existir, em algum momentos, uma crítica que, não sendo necessariamente tecnofóbica, alerta para os perigos dos avanços tecnológicos desenfreados, como a velocidade violenta e opressora a que o ser humano se encontra sujeito nos dias de hoje. A propósito da relação entre tecnologia e velocidade, diz-nos Tavares numa entrevista a Cristina Margato: "A velocidade da tecnologia já não é humana, abre um espaço que pode ser perigoso ou não controlável. A partir de uma certa velocidade deixamos de ver, a cegueira é fisicamente comprovável e é simbolicamente interessante" (Tavares, 2019). Poderíamos agrupar estas ideias do autor da seguinte forma: a velocidade da tecnologia não é humana e produz uma cegueira que ajuda a adensar o caos, a desordem e a violência que existe no mundo (por vezes em quantidades insuportáveis). Precisamente sobre a desordem do mundo, a maldade, o progresso e a tecnologia, encontramos esta reflexão em Uma Viagem à Índia:

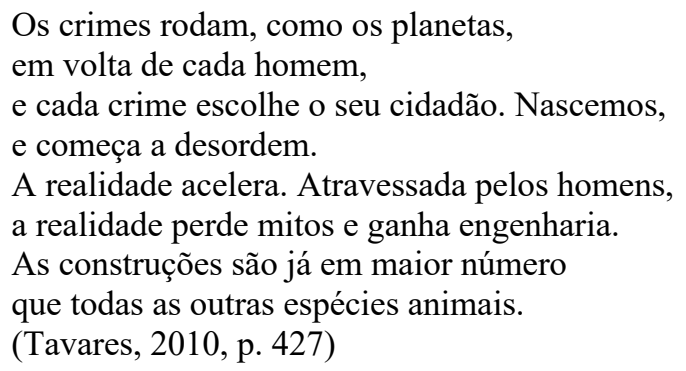

Ainda a respeito da questão desta espécie de tirania do tecnológico no mundo contemporâneo, no Canto I da epopeia tavariana encontramos um apontamento irónico que nos dá conta da diferença entre o passado e o presente:

Cascos dos cavalos substituídos em apenas dois séculos por pneus (que aderem melhor à realidade que os mamíferos). A vida é agora habitada por máquinas (sem cheiro) e certas marcas de indústria potentes ganham, a cada dia, o nome que os grandes conquistadores perderam (Tavares, 2010, p. 56). 
Ainda na estância seguinte, afirma-se: "Nas mitologias, a fábrica e as máquinas/ ocuparam o lugar dos imperadores/ e do unicórnio. Eis o progresso da imaginação, pensa Bloom" (p.56). Complementando este paralelismo entre o antes e o agora, encontramos igualmente uma referência ao Destino, à crença e a sua relação contemporânea com a máquina e a tecnologia quando Bloom nos diz: "Quando o nosso Destino não funciona/ (como um motor), o melhor é inventar-se/ uma nova maquina ou uma nova crença" (Tavares, 2010, p. 142). Ou uma crença numa nova máquina, diríamos.

4.

Novamente a respeito da máquina, importa referir que Gonçalo M. Tavares faz, por diversas vezes, uso de uma imagem curiosa que compara a natureza humana a uma máquina com dois motores, o da bondade e o da maldade: "Temos dois motores em funcionamento", diz-nos, "o de fazer atos maldosos e um para atos bondosos" (Tavares, 2010a). Nessa mesma entrevista, o autor alerta ainda para o facto de "nenhum de nós está fora do barco da maldade" (Tavares, 2010a). Em Uma Viagem à Índia, existe uma passagem que ilustra de forma perfeita a tendência e a preponderância da maldade no humano apesar de todo o progresso, apesar de todos os avanços:

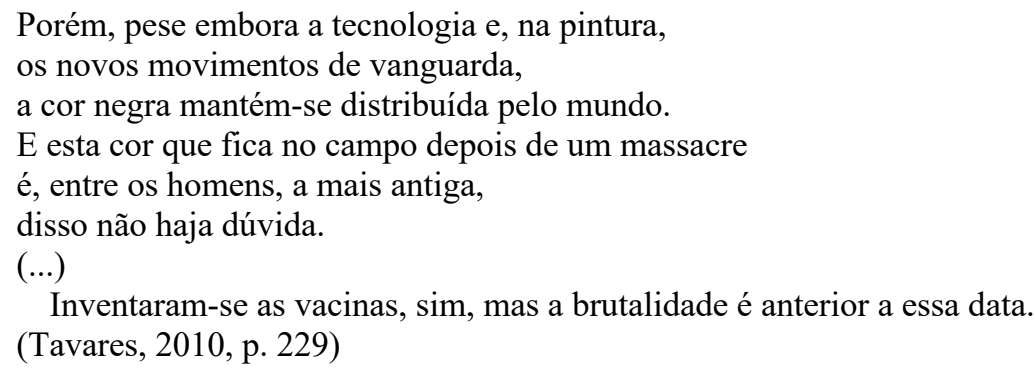

A referência anterior à máquina da maldade lembra-nos, pois, a guerra, o conflito armado, que em Gonçalo M. Tavares significa, muitas vezes, a Segunda Guerra Mundial e a memória dos horrores do Holocausto, presentes sobretudo nos livros da série $O$ Reino. Desde sempre, os conflitos entre os homens foram importantes impulsionadores de invenções e inovações tecnológicas. Tal aconteceu de forma exponencial durante a Segunda Guerra Mundial naquele que Eduardo Lourenço chamou o "mais fascinante e atroz dos séculos" (Lourenço, 2007, p. 11). A partir da destruição e da maldade, o ser humano cria algo novo e a maior parte dos desenvolvimentos a que continuamos a assistir nos dias de hoje, ao nível da tecnologia, ciência e mesmo medicina, teve como resultado os avanços científicos e tecnológicos feitos em nome do conflito e do confronto. A sua origem foi, portanto, essa cor negra que se espalha de forma voraz por todo o (relativamente breve) período de existência humana, nessa brutalidade que é, de facto, anterior, à invenção das vacinas. É partindo deste ponto de vista que devemos entender a posição cautelosamente distante de Tavares em relação à tecnologia e aos avanços científicos responsáveis pela aceleração vertiginosa da vida humana no século XXI e que encontra eco em diversos momentos das suas obras, em especial, como vimos, nos livros pretos da tetralogia $O$ Reino e noutros que poderemos dizer que partilham com esses quatro a insistência e persistência da cor negra no mundo, como é o caso de Uma Menina estava perdida no seu século à espera do pai, Água, Cão Cavalo, Cabeça e Uma Viagem à Índia.

Vemos, então, que é a partir deste entendimento das coisas que advém a posição antropologicamente pessimista do escritor, a perceção lúcida da necessidade de cautela, da 
necessidade de imprimir um pouco mais de lentidão ao mundo, com recurso, por exemplo, à leitura e, em específico, ao ato de manusear o objeto livro, as suas páginas, a lombada e a contracapa. Numa conversa com Raquel Ribeiro, acerca da relação entre ciência e literatura, Tavares refere o perigo da excessiva especialização do cientista, chamando a atenção para o facto de “(...) muita da história trágica do século XX [ter sido] uma história em que, de certa maneira, a ciência foi utilizada, instrumentalizada, manipulada pela política". Os cientistas estavam "obcecados pelo como" e "nunca perguntaram para quê e porquê" (Tavares citado em Ribeiro, 2014). De acordo com o autor, é precisamente aí que entra a responsabilidade do escritor através da produção de uma literatura lúcida que olhe para a realidade contemporânea de forma não compartimentalizada e não essencialista, e que chame a atenção para a instrumentalização da ciência decorrente da obsessão pela superespecialização e do perigoso princípio de "investigação pela investigação". Falando especificamente de literatura, o posicionamento pós-humano encara-a não como mero repositório ou perpetuação de uma já ultrapassada conceção de humanismo, mas precisamente como o lugar a partir do qual se faz um questionamento da existência humana ou de determinadas conceções de existência humana, tal como acontece na literatura tavariana.

Gonçalo M. Tavares defende, então a importância do ato de leitura, concebendo o livro como uma "máquina da lentidão" (Tavares, 2011), que ajuda o leitor a abrandar do ritmo frenético do quotidiano contemporâneo. Jonathan Franzen fala-nos de algo semelhante quando afirma a incompatibilidade da lentidão requerida pelo ato de leitura e "the hyperkinesis of modern life" (Franzen, 2002, p. 63). Ainda assim, Franzen diz acreditar na importância e no poder do ato de leitura, considerando-os, como Jeff Wallace, como uma estratégia de "choice and resistance" (Wallace, 2017), que adquire especial importância nestes tempos pós-humanos de proliferação de tecnologia e velocidade.

Escolha e resistência, precisamente aquilo que Gonçalo M. Tavares pretende fazer ao prescrutar as inquietações, as motivações e os medos do ser humano no século XXI, século completamente dominado pela tecnologia, que, segundo o autor em entrevista à revista Prelo, muda os nossos medos e gere as nossas tensões" (Tavares, 2017). E são precisamente as indagações acerca das "inquietações que a máquina introduziu" que levam o escritor, mais recentemente, a embarcar pelo mundo das Mitologias, com os títulos $O$ Homem Sem Cabeça e o Homem do Mau olhado e Cinco Meninos, Cinco Ratos que, de acordo com palavras do autor, "passam um pouco pelas histórias tradicionais, pelas lengalengas mas remetendo-as para o século em que nós estamos onde, mais uma vez, as máquinas se apresentam como personagens principais e não como paisagens" (Tavares, 2017). Com efeito, estes títulos recuperam reflexões, já iniciadas em obras como Uma Viagem à Índia e Breves Notas sobre Ciência, acerca do tipo de relação que as narrativas mitológicas mantêm com a realidade contemporânea da máquina e da tecnologia, na qual o ser humano é sempre já outro ou outra coisa, algo fluido, complexo e ambíguo, tanto para o (seu) bem, como para o (seu) mal.

\section{REFERÊNCIAS}

Badmington, N. (2003). Theorizing posthumanism. Cultural Critique, 53, Posthumanism (Winter, 2003), 1027. https://muse.jhu.edu/article/41107

Braidotti, R. (2011). Nomadic theory: The portable Rosi Braidotti. New York: Columbia University Press. 
Braidotti, R. (2013). The posthuman. Cambridge: Polity Press.

Braidotti, R. (2017). Posthuman, all too human: The memoirs and aspirations of a posthumanist. The 2017 Tanner Lectures Delivered at Yale University. https://bit.ly/371UPae

Braidotti, R. (2018). A theoretical framework for the critical posthumanities. Theory, Culture \& Society, 36(6), 31-61. https://bit.ly/371UPae

Ferrando, F. (2016). Humans have always been posthuman: A spiritual genealogy of the posthuman. In Banerji, D., Paranjape, M.R. (eds.). Critical Posthumanism and Planetary Futures (pp.243-256). Berlin : Springer. https://link.springer.com/chapter/10.1007/978-81-322$3637-5 \quad 15$

Franzen, J. (2002). Why bother? In How to be alone: Essays. Londres: Fourth Estate.

Hayles, K. N. (1999). How we became posthuman: Virtual bodies in Cybernetics, Literature, and Informatics. Chicago: The University of Chicago Press.

Henry-Lévy, B. (2018, August 22). We are not born human. The New York Times, Aug. 22. https://www.nytimes.com/2018/08/22/opinion/we-are-not-born-human.html

Herbrechter, S. (2013). Posthumanism: A critical analysis, London: Bloomsbury.

Lourenço, E. (2007). Esplendor do caos. 5. edição. Lisboa: Gradiva.

Malone, N. \& Ovenden, K. (2017). Natureculture. The International Encyclopedia of Primatology (Edited by Agustín Fuentes). John Wiley \& Sons, Inc. https://onlinelibrary.wiley.com/doi/pdf/10.1002/9781119179313.wbprim0135

Tavares, G. M. (2004). A máquina de Joseph Walser. Lisboa: Editorial Caminho.

Tavares G. M. (2006). Breves notas sobre Ciência. Lisboa: Relógio D’água.

Tavares, G. M. (2007). Aprender a rezar na era da técnica. Lisboa: Editorial Caminho.

Tavares, G. M. (2010). Uma viagem à Índia: Melancolia contemporânea (um itinerário). Lisboa: Editoral Caminho.

Tavares, G. M. (2010a). Português Gonçalo M. Tavares fala sobre maldade, Saramago e o Brasil, entrevista a Fábio Victor. Folha de S. Paulo, Julho. https://m.folha.uol.com.br/ilustrada/2010/07/767901-portugues-goncalo-m-tavares-fala-sobre-maldade-saramago-e-obrasil.shtml

Tavares, G. M. (2010b, outubro 27). Gonçalo M. Tavares - O romance ensina a cair, entrevista a Pedro Mexia. Jornal Público, Suplemento "Ípsilon".

Tavares, G. M. (2010c). Gonçalo M. Tavares, entrevista a Carlos Vaz Marques. Revista Ler (dezembro), 30-38, 84.

Tavares, G. M. (2011, novembro 25). Não há nenhuma máquina idêntica ao livro, entrevista a Sérgio Oliveira. Jornal de Notícias/Revista Babel/Livros do Mundo.

Tavares, G. M. (2013). Atlas do corpo e da imaginação. Lisboa: Editorial Caminho. 
Tavares, G. M. (2017, julho). A leitura é só o início, entrevista a Tânia Pinto Ribeiro. Prelo, jul. 2017. http://prelo.incm.pt/p/texto-e-fotografias-tania-pinto-ribeiro.html

Ribeiro, R. (2014, agosto 24). Pode a literatura ser a ciência mais pura? Ipsílon, Jornal Público. https://www.publico.pt/2014/08/24/culturaipsilon/noticia/pode-a-literatura-ser-a-cienciamais-pura-1667195

Tavares, G. M. (2019, abril 19). Ser humano é a nossa mão tremer, entrevista a Cristina Margato. Expresso/Vida Extra, 19/4/2019. Disponível em: <https://vidaextra.expresso.pt/artes/2019-04-07-Entrevista-a-Goncalo-M.-Tavares-Ser-humano-e-a-nossa-mao-tremer>.

Wallace, J. (2017). Literature. Critical posthumanism network: Geneology of the posthuman, Cardiff: Metropolitan University. https://criticalposthumanism.net/literature/ 